\title{
Developing the DigiQUAL Protocol for Digital Library Evaluation
}

\author{
Martha Kyrillidou \\ Association of Research Libraries \\ 21 Dupont Circle, Suite 800 \\ Washington, DC 20036 \\ (202) 296-2296 \\ martha@arl.org
}

\author{
Sarah Giersch \\ Association of Research Libraries \\ 312 Severin St. \\ Chapel Hill, NC 27516 \\ (919) 960-8208 \\ sgiersch@bellsouth.net
}

\begin{abstract}
The distributed, project-oriented nature of digital libraries (DLs) has made them difficult to evaluate in aggregate. By modifying the methods and tools used to evaluate traditional libraries' content and services, measures can be developed whose results can be used across a variety of DLs. The DigiQUAL protocol being developed by the Association of Research Libraries (ARL) has the potential to provide the National Science Digital Library (NSDL) with a standardized methodology and survey instrument with which to evaluate not only its distributed projects but also to gather data to assess the value and impact of the NSDL.
\end{abstract}

\section{Categories and Subject Descriptors}

J.4 [Computer Applications]: Social and Behavioral Sciences -economics, psychology, sociology

\section{General Terms}

Measurement, Human Factors

\section{Keywords}

Digital Library Service quality; Evaluation; Libraries; Educational Digital Libraries

\section{INTRODUCTION}

As digital libraries (DLs) have evolved, so have the documented efforts of evaluating DL system design, implementation and use. For the most part, early research examined if and how people were using DLs; this data was fed into the design and development cycle. Very little work has been done to evaluate DLs in the context of teaching, learning or research. DL evaluation efforts are hindered by a lack of tools and methodologies such that "the conceptual state-of-the-art of digital library evaluation is not sufficiently developed to start with" [7].

Although they use different metrics and methods of data gathering, traditional libraries evaluate features that are paralleled

Permission to make digital or hard copies of all or part of this work for personal or classroom use is granted without fee provided that copies are not made or distributed for profit or commercial advantage and that copies bear this notice and the full citation on the first page. To copy otherwise, or republish, to post on servers or to redistribute to lists, requires prior specific permission and/or a fee.

JCDL '05, June 7-11, 2005, Denver, Colorado, USA.

Copyright 2004 ACM 1-58113-000-0/00/0004 ...\$5.00. in DLs, such as library use, effectiveness of services and patron demographics. Only recently have traditional, primarily academic, libraries begun to consider how to incorporate new measures of digital content and services, which will allow comparisons across different library settings and operations [5]. At the same time, traditional library evaluation "will be made even more complicated as teaching, learning and research become even more integrated with libraries' resources and services" [3].

The intersection between digital and traditional libraries provides fertile territory for adapting traditional library measures for use in the digital environment. This paper describes the Association of Research Libraries' (ARL) development of the DigiQUAL protocol for use in the National Science Digital Library (NSDL). DigiQUAL will measure DL service quality by building on the technical experience of, and using a similar mixed-methods design employed in, the LibQUAL+ ${ }^{\mathrm{TM}}$ protocol, which is used to measure service quality by traditional libraries. NSDL is collecting data about usage and content with standardized methods. Data from the DigiQUAL protocol will provide an additional perspective on NSDL's relative performance and importance to its users. Ultimately, these combined measures will be used to assess the value and impact of NSDL.

\section{CHALLENGES TO EVALUATING NSDL} NSDL was funded by the National Science Foundation (NSF) in 2000 to provide educational resources for science, technology, engineering and mathematics education and to deepen and extend science literacy. Since its inception, NSDL has been challenged to demonstrate its value and impact. Initial efforts by the NSDL Education Impact and Evaluation Standing Committee (EIESC) highlighted how the distributed, project-oriented nature of NSDL posed competing challenges to evaluating NSDL as an entity and evaluating contributions of individual projects $[1,8]$. One of the recommended solutions was to develop common methodologies and reporting instruments for sharing data. Recently, the EIESC has undertaken another pilot study to measure usage with standardized methodologies and tools across multiple DLs [4]. The DigiQUAL protocol will provide another standardized methodology and tool set for NSDL.

\section{DIGIQUAL DEVELOPMENT}

Both the LibQUAL+TM and DigiQUAL protocols build on the theoretical foundations of the gap theory of service quality, and in particular, on the SERVQUAL measurement of the gap between customers' expectations and perceptions of service quality. 
After four years (2000-03) of iterative implementation and continuous qualitative and quantitative regrounding, LibQUAL $+^{\mathrm{TM}}$ has evolved into a scalable, web-based, total market survey with twenty-two items that measure three dimensions of library service quality: library as place, information control, and affect of service [2]. Following a similar process, the DigiQUAL protocol will eventually result in a standardized model for evaluating service quality that can be used across a variety of digital libraries.

\subsection{DigiQUAL Methodology}

Development of the LibQUAL+ ${ }^{\mathrm{TM}}$ protocol began with libraries testing 41 items along five dimensions of service quality. Similarly, the first phase of DigiQUAL protocol development (2003-04) began with DLESE and MERLOT user focus groups identifying 180 items linked to twelve themes related to DL service quality: design features; accessibility/navigability; interoperability; DL as community for users, developers and reviewers; collection building; role of federations; copyright; resource use; evaluating collections; and DL sustainability [6].

During the second phase of protocol development (spring 2005), subsets of the 180 items will be tested with five pilot sites who are part of NSDL (DLESE, iLumina, the Math Forum, MERLOT, NEEDS) and NSDL.org. Unlike academic libraries that participated in early LibQUAL+ ${ }^{\mathrm{TM}}$ testing, pilot DLs' collections and users vary widely. When testing DigiQUAL, DLs will select only the items which are relevant to their sites' services. The purpose of this process is to validate the items across a range of audiences, disciplines and DLs. A potential challenge is that the pilot DLs are so diverse that there will be no commonality among the items they select.

To test items with DL users, ARL will develop a web-based survey form consisting of five questions randomly chosen from the subset of DL-specific items, plus one question concerning users' overall satisfaction with the site. Users will rate each item on two factors: personal importance and the DLs' performance. DLs will select the most appropriate method for notifying users of the survey (e.g., a popup window; a link on the homepage; or an email). Further research is needed to determine which notification method is most effective for particular DL audiences.

\subsection{Implementation Concerns}

Pilot DLs shared similar concerns when planning to take part in the second phase of DigiQUAL protocol development, highlighting again the challenges of adapting traditional library measures for use in DLs and of evaluating NSDL instead of individual projects.

Unlike academic libraries, whose staff knows its (adult) audience and can control sample size based on enrollments or employment figures, DLs often have no idea about the age of their users or the size of their audience base. This could affect how the survey is deployed and how results are interpreted. Analysis of DigiQUAL data in conjunction with usage data may provide a direction for future survey deployment and analysis.

Another concern of pilot DLs was how survey data will be reported. Even though the goal of DigiQUAL is to be able to share evaluation results across DLs, pilot sites did not want individual DL results made public as this could negatively impact site use and reputation when compared with other sites. For this pilot study, data will only be published in aggregate. However, the ability to present a DL's score within the normative context of other data will be explored with the participating sites.

\section{CONCLUSION}

Even in its early stages, the pilot study used to test the DigiQUAL protocol has identified issues unique to evaluating DLs. However, pilot DLs see the benefit of participating in this study. They are motivated by being good citizens of the DL community and are hopeful that enough data would be gathered to produce reports that help them better respond to user needs. DLs are willing to consider sharing individual site results in the future if a process for sharing anonymized data is developed. This would establish a precedent, and a means, for cross-project data sharing. After testing and analysis in spring and summer of 2005, the DigiQUAL protocol will be reviewed for scaling across NSDL and beyond.

\section{ACKNOWLEDGMENTS}

This work is supported in part by ARL and by a grant (DUE0121769) from the National Science Foundation.

\section{REFERENCES}

[1] 2003 Evaluating Education Impact Workshop. http://eduimpact.comm.nsdl.org/evalworkshop/index2.php

[2] Cook, C., Heath, F., Kyrillidou, M., et al. (2003). Developing a National Science Digital Library LibQUAL+ ${ }^{\mathrm{TM}}$ Protocol: An E-service for Assessing the Library of the 21st Century. Washington, D.C.: Association of Research Libraries.

[3] Everest, K. and P. Payne (2001). "The impact of libraries on learning, teaching and research: Report on the LIRG seminar held in Leeds, 30th. October 2001." Library and Information Research News 25(81): 18-22.

[4] Jones, C., Giersch, S., Sumner, T., et al. (2004). Developing a Web Analytics Strategy for the National Science Digital Library. D-Lib Magazine, 10(10).

[5] Kyrillidou, M., \& Giersch, S. (in press). Qualitative Analysis of ARL E-Metrics Participant Feedback about the Evolution of Measures for Networked Electronic Resources. Library Quarterly.

[6] Lincoln, Y. S., Cook, C., \& Kyrillidou, M. (2004). Evaluating the NSF National Science Digital Library Collections: Categories and Themes from MERLOT and DLESE. Paper presented at the MERLOT International Conference, Costa Mesa, California.

[7] Saracevic, T. (2000). "Digital library evaluation: Toward an evolution of concepts." Library Trends 49(2): 350-369. http://scils.rutgers.edu/ tefko/LibraryTrends2000.pdf

[8] Sumner, T., Giersch, S., \& Jones, C. (2003). Steps Towards Establishing Shared Evaluation Goals and Procedures in the National Science Digital Library. Poster presented at the Joint Conference on Digital Libraries 2003, Houston, Texas. 